\title{
Comparison and Analysis of Metropolitan Power Grid Partition in China and Abroad
}

\author{
Nan Yang, Qingfang Yuan \\ Jian Sun, Haiyun Wang \\ Beijing Electric Power Research Institute \\ Beijing, China \\ e-mail: 814326695@qq.com
}

\author{
Liangyu Li, Hengrui Ma \\ Li Lin \\ North China Electric Power University \\ Beijing, China \\ e-mail: liliangyugood@163.com
}

\author{
Shaomin Zhu \\ Chaoyang Power \\ Company of Beijing \\ Beijing, China \\ e-mail: 44754921@qq.com
}

\begin{abstract}
With grid expansion in China, many metropolitan power grids have been divided into partitions at $220 \mathrm{kV}$ to reduce the system short-circuit current and make the grid structure clearer. However, there are still a lot of problems with the current domestic (Chinese) grid partitioning. In contrast, urban power grids of developed countries are fully developed, and their partition operation experience can be reference for domestic urban power grids. In this paper, the grid partitioning situation of domestic cities, especially Shanghai power grid, is presented and analyzed. Then, similar work is done to analyze the grid partition status quo of New York and Tokyo of which grid partition features are prominent. Finally, the metropolitan power grid partition situation in China and abroad is comparatively analyzed to provide reference for the Chinese urban power grids.
\end{abstract}

Keywords-metropolitan power grid; power grid partition; Shanghai grid; New York City grid; Tokyo grid

\section{INTRODUCTION}

In recent years, along with the size of power grid increasing, research on power grid partitioning has been concerned, and power grids in Chinese metropolises such as Beijing, Shanghai have been divided into partitions. In fact, for large urban power grid characterized by concentrated load and tight structure, grid partition is an inevitable trend $[1,2]$.

Currently, domestic power grid is still in a period of rapid development, power grids of economy developed metropolises have initially formed partition structure. But there are still many problems for current network partition: different partitions are unevenly developed, the short circuit current level of some partitions is still high, and the reliability of partial power grid partitions is poor; most of the existing power grid partitions cannot accommodate to the future development. Compared to the rapid expansion of Chinese power grid, urban power grids of developed countries are relatively mature and their operation experience of grid partition can be reference for Chinese urban power grids.

The rest of this paper is organized as follows. Section II describes domestic grid partition situation, emphatically analyzes Shanghai grid partition status. Grid partition situation of New York is presented and analyzed in Section III and Tokyo in section IV. The grid partition situation of foreign cities New York, Tokyo as well as domestic cities are compared and analyzed, and reference for the domestic urban grids is given in section V. The paper is concluded in section VI.

\section{DOMESTIC POWER GRID PARTITION ANALYSIS}

Main voltages of transmission grid in china are $500 / 220 \mathrm{kV}$, and the grid partitions at $220 \mathrm{kV}$. The main purpose of network partitioning is to reduce the large shortcircuit current of $220 \mathrm{kV}$ system. Short-circuit current of $220 \mathrm{kV}$ bus bars at $500 \mathrm{kV}$ substations is most likely to exceed the rated value. And in all the measures to limit the short circuit current, the appropriate partitioning at $220 \mathrm{kV}$ is fundamental [3].

\section{A. Research and Application Situation of Metropolitan Power Grid Partition in China}

The structure of each $220 \mathrm{kV}$ grid partition is as follows: one or more $500 \mathrm{kV}$ substations and the generators in a partition supply the $220 \mathrm{kV}$ partition, $220 \mathrm{kV}$ power lines in each $220 \mathrm{kV}$ partition form radial or partial ring network architecture [4]. Typical structure of a grid partition in domestic big cities is shown in Fig. 1. 


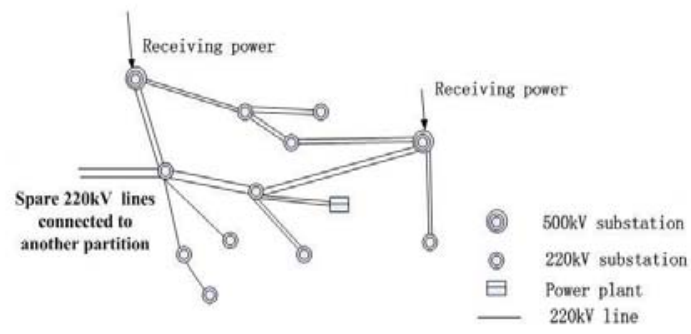

Figure 1. Typical structure of a grid partition in domestic big cities

According to power grid partitioning principles [5,6], each partition generally needs to meet the following requirements: contact between each $220 \mathrm{kV}$ partition and $500 \mathrm{kV}$ main grid should be strong enough to ensure that any failure will not cause $220 \mathrm{kV}$ partition isolated operation [7]; Active and reactive power can keep balance in each partition; the voltage/reactive power adjustment can ensure qualified bus voltage in each $220 \mathrm{kV}$ partition; certain scale power units should exist in a partition; spare $220 \mathrm{kV}$ interconnection lines should be retained between adjacent partitions.

For a larger partition that meets conditions of splitting into smaller partitions, partitioning schemes are made considering the actual grid situation. So, different partition schemes are assessed through comparison of the pros and cons of the following aspects: power flow analysis, short circuit current calculation and analysis, static security analysis and stability analysis $[8,9]$.

\section{B. Shanghai Grid Partition Analysis}

Since China is still in the process of urbanization, metropolitan power grids develop fast, and grid partition structure is still in the formative period. There are still many problems with current power grid partition. For example, $220 \mathrm{kV}$ network partition situation of Shanghai power grid is analyzed as follows:

- $220 \mathrm{kV}$ partitions are electrically independent in normal condition. The main problems of each partition are thermal, voltage stability and frequency stability after partition splitting [10].

- Isolated operation ability of some partitions is poor. Because generating units output accounts for a large proportion of partition capability; once unstable operation of large units occurs, the entire partition may collapse [11].

- Big difference exists in generating capacity of partitions. There is no generator in some partitions.

- dynamic reactive power compensation capacity is insufficient in some partitions [12].

- Mutual supply ability between partial power grid partitions is weak.

- For partitioned power grid, short-circuit current level of major station bus bars has been effectively controlled, but three-phase short-circuit current of some partitions still overrates. Currently, pulling up lines, connecting series reactors, bus splitting and other measures are taken to control short-circuit current at the cost of sacrificing some reliability margin.

\section{NEW York City GRID PARTITION ANALYSIS}

\section{A. Grid Partition Overview}

Electricity consumption of New York City is vast, but the receiving-end structure characteristic is not that obvious [13]. Transmission grid voltages of New York area are $500 / 345 / 230 / 138 \mathrm{kV}$, and underground cables are used in downtown with voltages 345/138/69kV.

There are 17 partitions in New York City grid; these partitions are also known as transmission load areas (TLAs). The highest transmission voltage rating of a partition is $345 \mathrm{kV}$ or $138 \mathrm{kV}$ [14]. The general structure of a partition is shown in Fig. 2 below. A power grid partition in New York City usually consists of several transmission substations, regional substations (regional substations supply power to electrically independent regions), load and internal generation, and is connected with the other partitions through interconnection lines.

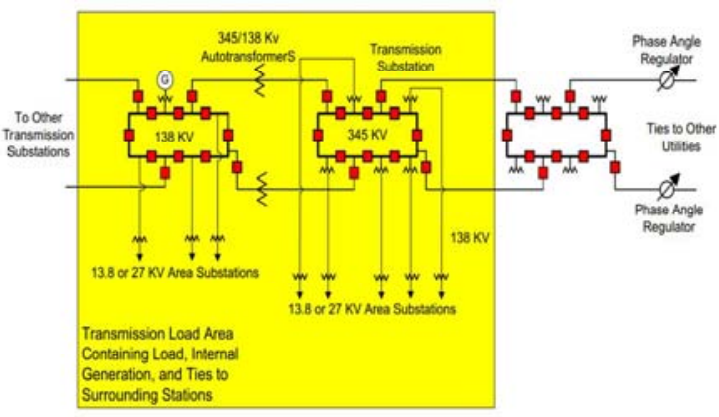

Figure 2. General structure of a New York City grid partition

\section{B. Grid Partition Analysis}

New York City grid partition situation is analyzed from the following aspects:

1) Power supply margin. There is large margin of the New York City electricity supply relative to the predicted load demand. NYSRC provides that the probability (or risk) of disconnecting any firm load due to resource deficiencies shall be, on average, not more than once in ten years [15].

2) Power units in a partition. Usually, certain scale generating units exist in a partition. Generators in a partition are required to provide active/reactive power as well as black start capacity.

3) Partition contingency level. Specific contingency level is required for each partition, which means that the system can return to normal state when certain contingencies occur. Partitions of New York City grid and corresponding contingency levels are listed in TAB. 1 below. 
TABLE I.

NEW YORK CITY GRID PARTITIONS

\begin{tabular}{|c|c|c|}
\hline No. & Partition & $\begin{array}{c}\text { Design } \\
\text { Contingency } \\
\text { Level }\end{array}$ \\
\hline 1 & New York City-345kV & Second \\
\hline 2 & West 49th Street-345kV & Second \\
\hline 3 & New York City-138kV & Second \\
\hline 4 & Astoria- $-138 \mathrm{kV}$ & Second \\
\hline 5 & East 13th Street-138kV & Second \\
\hline 6 & Astoria East/Corona - $138 \mathrm{kV}$ & Second \\
\hline 7 & Astoria West/Queensbridge-138kV & Second \\
\hline 8 & Vernon-138kV & Second \\
\hline 9 & East River-138kV & Second \\
\hline 10 & Greenwood/Staten Island-138kV & First \\
\hline 11 & Corona/Jamaica-138kV & First \\
\hline 12 & Bronx-138kV & First \\
\hline 13 & Eastview-138kV & First \\
\hline 14 & Staten Island-138kV & First \\
\hline 15 & $\begin{array}{l}\text { Dunwoodie North/Sherman Creek- } \\
138 \mathrm{kV}\end{array}$ & First \\
\hline 16 & Dunwoodie South-138kV & First \\
\hline 17 & Millwood/Buchanan-138kV & First \\
\hline
\end{tabular}

First contingency design means that when single contingency of a-g (a-g are the numbers of the contingencies stipulated by NYSRC) occurs, applicable post-contingency thermal, voltage and stability limits shall not be exceeded and the system must be able to be returned to within its normal state limits. In addition to the conditions first contingency design requires, second contingency design prescribes that when $\mathrm{a}$ and $\mathrm{d}$ (a refers to three-phase permanent fault of generators, transmission lines, transformers or buses with normal removal time, d refers to non-fault loss of any component) occur, system can return to normal state [16].

4) Partition reliability study in the power grid planning. There is a 10-year plan of New York City power grid, and partitioned grid reliability is studied annually at 5-year and 10 -year planning horizon. Reliability related calculation and analysis are performed by partitions in the following areas: power flow (thermal and voltage stability analysis), shortcircuit current, stability, critical clearing time, under frequency load shedding, transient switching surge and lightning withstand capabilities and extreme contingencies. Reliability calculation methods and evaluation requirements are specified by appropriate criteria [16].

If considering power flow control methods, reliability of some partitions still cannot meet the corresponding criteria, strategies for the resolution of deficits through system enhancements are listed below: (1) Load transfers, (2) Upgrades to infrastructure. (3) New generation or transmission stations, (4) Installation of reactive power compensation devices (capacitors or reactors) or power flow control devices (phase angle regulators and variable frequency transformers), (5) Short circuit current remediation, and (6) Demand Side Management (DSM). Specific measures are adopted considering the extent of impact, reliability improvement, scheduling, and cost.

\section{TOKYO GRID PARTITION ANALYSIS}

\section{A. Grid Partition Overview}

Tokyo grid is a receiving-end grid. Voltages of Tokyo grid are $1000 \backslash 500 \backslash 275 \backslash 154 \backslash 66 \backslash 22 \backslash 6.6 \mathrm{kV}$, and the transmission grid voltages are $1000 / 500 / 275 \mathrm{kV}$. Tokyo grid structure is shown in Fig. 3.

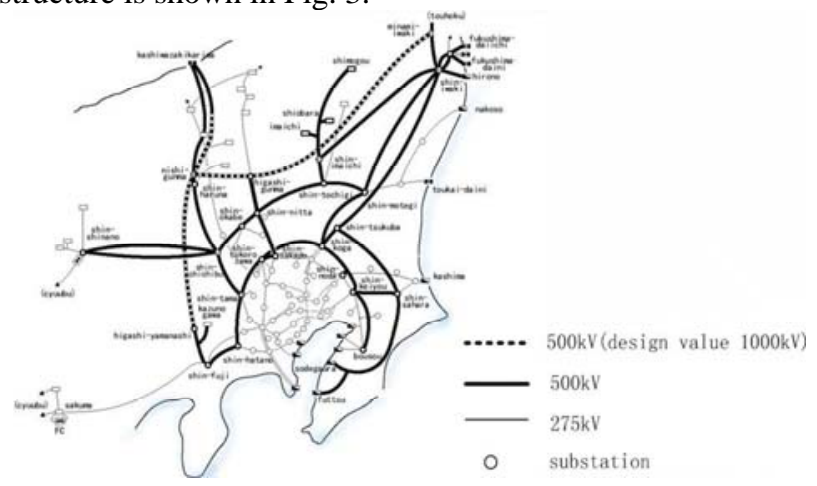

Figure 3. Tokyo grid structure

$500 \mathrm{kV}$ and $1000 \mathrm{kV}$ UHV transmission lines form triple clamp ring around Tokyo Bay [17]. Tokyo $275 \mathrm{kV}$ grid is divided into a number of radial partitions, also called subpower systems. Each sub-system receives power from the $500 \mathrm{kV}$ ring network through the $275 \mathrm{kV}$ transmission lines and underground cables $(275 \mathrm{kV}$ cables supply power to the city center) [18].

\section{B. Grid Partition Analysis}

Tokyo power grid partition situation is analyzed below:

1) Main grid structure. Main network of Tokyo grid is strong, the grid structure is clear. The UHV triple clamp ring network is the foundation of Tokyo $275 \mathrm{kV}$ partitions, which accepts electricity from surrounding areas of Tokyo, and supplies power to partitions in city center by $275 \mathrm{kV}$ radial cables.

2) Short-circuit current limitation. To limit the shortcircuit current of $275 \mathrm{kV}$ power network, part of the $275 \mathrm{kV}$ bus bars adopt splitting operation. The $275 \mathrm{kV}$ bus coupler as a liaison between adjacent partitions, is disconnected during normal operation, and closed in case of accidents so that adjacent partitions can provide supportive power. Also high impedance transformers are chosen in $500 \mathrm{kV}$ downtown substations to limit the short circuit current.

3) Reactive power/voltage regulation in a partition. Generally, there are power units in a partition, but the generation capacity is far less than the load demand. So, reactive power regulation ability of generating units is limited, OLTCs (on load tap changing transformers) with rated voltages $525 \mathrm{kV} / 285 \mathrm{kV}$ and taps $\pm 8.5 \%$ are used to improve the reactive power/voltage regulation ability in partitions [19].

4) Islanding protection system in a partition. There is islanding protection system to prevent politically and 
economically important loads in a partition from power outage [20]. When islanding protection system detects insufficient power supply capacity in a partition caused by failures like transmission line fault, high-speed load shedding is initiated in case that the system may collapse as a result of generator under frequency tripping. With under frequency load shedding actions, reactive power compensation needs to be reduced to ensure reactive power balance in a partition.

\section{COMPARATIVE ANALYSIS OF FOREIGN AND DOMESTIC GRID PARTITION}

Comparing power grid partition situation of big cities in China and abroad, the partitioned grid structure and operation experience of New York, Tokyo can be summarized as the following points for reference:

- There is large power supply capacity margin relative to the load demand of New York City grid; while main grid structure of Tokyo is clear and strong. Reliable power supply for grid under partition operation is on the premise that there is sufficient power source, and the main grid structure is strong.

- In terms of the partition structure, there is certain scale generator sets in every partition of foreign metropolitan grids, and the generator sets in a partition is required to provide black start capacity. Mutual power supply capability between adjacent partitions is required both in China and abroad, but the domestic grid partition is still in a formative stage, some of the grid partitions lack the ability to supply electricity to other partitions. And mutual supply ability of adjacent partitions in Chinese metropolitan grids should be improved with transmission line construction, and operation mode adjustment.

- There are specific contingency levels of New York City grid partitions. Comprehensive grid reliability simulation and analysis are conducted for each partition in the grid planning process. The simulation tools and analysis methodologies are clearly documented. Domestic institutions may do the same work in the network planning and develop corresponding criteria for partitioned power grid.

- Tokyo power grid partition is well developed. By contrast, domestic institutions should accelerate research on many issues about partitioned grid operation. Relevant issues include voltage stability, reactive power compensation, short-circuit current limiting measures in partitions, and mutual supply ability between partitions, and any other possible issues.

\section{CONCLUSION}

This paper summarizes the research and application status of metropolitan power grid partition in China. The current situation of New York, Tokyo grid partition operation is analyzed. Comparative analysis of grid partition status quo in China and abroad is made to provide reference for domestic urban grids.

On the whole, Chinese metropolitan grid partition still needs further improvement. Structure of power grid partitions needs to be strengthened, combining with construction of power grid and power sources. It is necessary to conduct comprehensive analysis of the reliability of power grid by partition so that countermeasures can be proposed against possible problems that may arise in the planning years. And appropriate guidelines should be developed to specify the calculation and analysis process. Research on related issues of power grid under partition operation should be carried on in advance to ensure security and reliability of electricity supply.

\section{REFERENCES}

[1] L. Teng, G. Wang, Y.P. Qiu, W.Z. Guo and Y. Zhan, "Tentative idea on layering and zoning of Anhui $500 \mathrm{kV} / 220 \mathrm{kV}$ grids,” East China Electric Power, vol. 34, no. 11, pp. 56-59, 2006.

[2] D. Nie, H.B. Sun, C.X. Nie and X.S. Li, "Layering and zoning study on Chongqing 500kV/220kV grids," Central China Electric Power, vol. 21, no. 5, pp. 19-21, 2008.

[3] D.K. Zhu, "Considerations on Shanghai 500kV grid plan modification and short-circuit current controlling," East China Electric Power, vol. 35, no. 1, pp. 41-44, 2007.

[4] X. Xu, T. Ding and Q.L. Wan, " $220 \mathrm{kV}$ power grid district-dividing optimization for limiting fault current,” Automation of Electric Power Systems, vol. 33, no. 22, pp. 98-101, 2009.

[5] C.Y. Li, S. Li, J.F. Shang and T.Z. Huang, "Comparison of operation mode of electromagnetic loop network and voltage-grading \& districtdividing,” Journal of Electric Power, vol. 21, no. 2, pp. 160-163, 2006.

[6] W.F. Yao, "Study on the sub-area power supply for Guangdong power grid during "12th Five-Year” period," Southern Power System Technology, vol. 5, no. 6, pp. 86-89, 2011.

[7] S.Z. Lu, W. Hu and J.Y. Luo, "Research on voltage grading and network partition of Jiangsu Grid,” Jiangsu Electric Engineering, vol. 25, no. 3, pp. 11-13, 2006.

[8] S.Y. Liu, Q. Gu, L.J. Zhang and C. Liu, "Research on Power Supply Scheme Based on Partitioning of 500/220 kV Tianjin Power Grid During the 11th Five-Year Plan,” Power System Technology, vol. 32, no. 9, pp. 51-55, 2008.

[9] X.Y. Mao, “A mid forward-term analysis on safety and stability in Zhejiang power grid under district-classified and voltage-classified operation,” East China Electric Power, no. 9, pp. 11-14, 2001.

[10] W. Wang and W.H. Wang, "Features and challenges of Shanghai power grid,” East China Electric Power, vol. 40, no. 5, pp. 754-757, 2012.

[11] F. Gao, "Low frequency load shedding improvement of Shanghai power grid under partition operation,” East China Electric Power, no. 5, pp. 7-9, 2001.

[12] Z.Q. Yuan, H. Tan and Y.Q. Ruan, "Optimal configuration of reactive power in Shanghai electric power network," East China Electric Power, vol. 37, no. 8, pp. 1275-1278, 2009.

[13] Chapter 17: Energy. [Online]. Available: http://www.nyc.gov/html/hpd/downloads/pdf/Chapter-17-Energy.pdf.

[14] M. Koenig. Updates to the Consolidated Edison long-range transmission plan for 2012. [Online]. Available: http://www.nyiso.com/public/webdocs/markets_operations/committee s/bic_espwg/meeting_materials/2012-1024/Review_of_Changes_to_the_Con_Ed_LRP_for_2012__For_NYISO.pdf.

[15] New York State Reliability Council, L.L.C., NYSRC Reliability rules for planning and operating the New York State Power System. [Online]. 
http://www.nysrc.org/pdf/Reliability\%20Rules\%20Manuals/RR\%20 Manual\%2029\%201-7-11\%20Final.pdf.

[16] Consolidated Edison Company of New York, Inc., Transmission Planning Criteria. [Online]. Available: http://www.nyiso.com/public/webdocs/markets_operations/services/pl anning/Documents_and_Resources/FERC_Form_715_Filing/Plannin g_Reliability_Criteria/ARCHIVE/ConEdison_Transmission_Plannin g_Criteria_EP-7100-6_June2008.pdf.

[17] E. ZAIMA and H. OKAMOTO, "Issues on UHV AC transmission lines of TEPCO in upgrading existing $1100 \mathrm{kV}$ designed lines from $550 \mathrm{kV}$ to $1100 \mathrm{kV}$," Proceedings of the CSEE, vol. 29, no. 22, pp. 4652, 2009.
[18] S. Imai and T. Yasuda, Islanding Protection with Active and Reactive Power Control, Japan: Tokyo Electric Power Company, Inc., 2009.

[19] L.H. Li and K. Gao, "Design and construction of the $500 \mathrm{kV}$ underground substation and cable in Tokyo, Japan,” International Electric Power For China, vol. 9, no. 6, pp. 38-41, 2005.

[20] S. Agematsu, S. Imai, R. Tsukui, H. Watanabe, T. Nakamura and T. Matsushima, "Islanding protection system with active and reactive power balancing control for Tokyo Metropolitan power system and actual operational experiences,” Developments in Power System Protection, IEE Seventh International Conference on, 2001, pp. 351354. 